\title{
The natural course of supravalvar aortic stenosis and peripheral pulmonary artery stenosis in Williams's syndrome ${ }^{\star}$
}

\author{
NIELS G GIDDINS, JOHN P FINLEY, MAURICE A NANTON, DOUGLAS L ROY \\ From the Cardiology Department, Izaak Walton Killam Children's Hospital, Halifax, Nova Scotia, Canada
}

SUMMARY The haemodynamic findings from two serial cardiac catheterisations in ten patients with Williams's syndrome were reviewed. The median ages at study were one and nine years. Raised mean (SD) left ventricular peak systolic pressures associated with supravalvar aortic stenosis increased significantly with time from 121 (25) $\mathrm{mm} \mathrm{Hg}$ to 153 (29) $\mathrm{mm} \mathrm{Hg}$. The peak systolic pressure drop between the left ventricle and aorta (measured in seven patients) increased significantly from 25 (25) $\mathrm{mm} \mathrm{Hg}$ to 50 (35) $\mathrm{mm} \mathrm{Hg}$. Raised right ventricular peak systolic pressure associated with peripheral pulmonary artery stenosis (in eight patients) decreased significantly with time from $52(26) \mathrm{mm} \mathrm{Hg}$ to $28(6) \mathrm{mm} \mathrm{Hg}$.

Supravalvar aortic stenosis in Williams's syndrome seems to progress rapidly, and careful monitoring is indicated. There is a strong likelihood that peripheral pulmonary artery stenosis in Williams's syndrome will improve spontaneously with time.

Williams's syndrome is characterised by unusual facies, abnormal growth and development, and variable cardiovascular anomalies. The most common of these are supravalvar aortic stenosis and peripheral pulmonary artery stenosis; but other lesions have been described, including pulmonary valve stenosis, septal defects, and peripheral systemic arterial stenosis. ${ }^{1}$

Studies of the natural course of these cardiovascular anomalies are limited. ${ }^{23}$ We report the results of serial cardiac catheterisation in ten patients with Williams's syndrome who had supravalvar aortic stenosis or peripheral pulmonary artery stenosis or both.

\section{Patients and methods}

The ten patients were referred to and followed at the Izaak Walton Killam Children's Hospital in Halifax, Nova Scotia. These were all of the patients in whom

Requests for reprints to Dr Niels G Giddins, Variety Children's Heart Centre, 685 William Avenue, Winnipeg, Manitoba R3E OZ2, Canada.

* Presented in part at the 59th Scientific Sessions of the American Heart Association, Dallas, Texas, USA in 1986.

Accepted for publication 11 April 1989 two cardiac catheterisations were indicated because of clinically important cardiovascular lesions, usually shown by grade $4 / 6$ cardiac murmurs or electrocardiographic findings typical of ventricular hypertrophy.

All had the characteristic features of Williams's syndrome, including distinctive facies and developmental delay. None had cardiovascular symptoms, and there was no contributory family history. Table 1 shows the age and sex of these patients. Six of them were boys.

Table 1 Study group

\begin{tabular}{|c|c|c|c|}
\hline \multirow[b]{2}{*}{ Patient } & \multirow[b]{2}{*}{ Sex } & \multicolumn{2}{|l|}{ Age (yr) } \\
\hline & & Cath 1 & Cath 2 \\
\hline $\begin{array}{c}1 \\
2 \\
3 \\
4 \\
5 \\
6 \\
7 \\
8 \\
9 \\
10 \\
\text { Mean } \\
\text { Median }\end{array}$ & $\begin{array}{l}\mathbf{F} \\
\mathbf{M} \\
\mathbf{F} \\
\mathbf{M} \\
\mathbf{F} \\
\mathbf{M} \\
\mathbf{M} \\
\mathbf{M} \\
\mathbf{M} \\
\mathbf{F}\end{array}$ & $\begin{array}{l}1 \mathrm{yr} \\
10 \mathrm{mth} \\
10 \mathrm{mth} \\
4 \mathrm{yr} \\
8 \mathrm{yr} 4 \mathrm{mth} \\
1 \mathrm{yr} 2 \mathrm{mth} \\
3 \mathrm{yr} 11 \mathrm{mth} \\
2 \mathrm{yr} 1 \mathrm{mth} \\
11 \mathrm{mth} \\
8 \mathrm{mth} \\
2 \mathrm{yr} 5 \mathrm{mth} \\
1 \mathrm{yr}\end{array}$ & $\begin{array}{l}9 \mathrm{yr} 8 \mathrm{mth} \\
8 \text { yr } 8 \mathrm{mth} \\
10 \mathrm{yr} 5 \mathrm{mth} \\
11 \mathrm{yr} 2 \mathrm{mth} \\
13 \mathrm{yr} 7 \mathrm{mth} \\
8 \text { yr } 6 \mathrm{mth} \\
8 \text { yr } 8 \mathrm{mth} \\
6 \mathrm{yr} 7 \mathrm{mth} \\
4 \mathrm{yr} 4 \mathrm{mth} \\
9 \mathrm{yr} 4 \mathrm{mth} \\
9 \mathrm{yr} 1 \mathrm{mth} \\
9 \mathrm{yr}\end{array}$ \\
\hline
\end{tabular}

Cath, catheterisation. 
Table 2 Left heart haemodynamic function

\begin{tabular}{|c|c|c|c|c|c|c|}
\hline \multirow[b]{2}{*}{ Patient } & \multicolumn{2}{|c|}{$\begin{array}{l}\text { Left ventricular } \\
\text { (LV) peak systolic } \\
\text { pressure (PSP) } \\
(\mathrm{mm} \mathrm{Hg})\end{array}$} & \multicolumn{2}{|c|}{$\begin{array}{l}\text { Aortic (Ao) } \\
P S P(m m \mathrm{Hg})\end{array}$} & \multicolumn{2}{|c|}{$\begin{array}{l}\text { LV-Ao PSP } \\
\text { gradient } \\
(\mathbf{m m} \mathbf{H g})\end{array}$} \\
\hline & Cath 1 & Cath 2 & Cath 1 & Cath 2 & Cath 1 & Cath 2 \\
\hline $\begin{array}{r}1 \\
2 \\
3 \\
4 \\
5 \\
6 \\
7 \\
8 \\
9 \\
10\end{array}$ & $\begin{array}{r}130 \\
100 \\
110 \\
170 \\
90 \\
83 \\
140 \\
120 \\
140 \\
130\end{array}$ & $\begin{array}{r}156 \\
170 \\
142 \\
200 \\
135 \\
150 \\
175 \\
145 \\
174 \\
87\end{array}$ & $\begin{array}{c}96 \\
\text { N/A } \\
110 \\
105 \\
90 \\
83 \\
84 \\
100 \\
\text { N/A } \\
\text { N/A }\end{array}$ & $\begin{array}{r}82 \\
135 \\
104 \\
82 \\
135 \\
75 \\
95 \\
115 \\
128 \\
82\end{array}$ & $\begin{array}{c}34 \\
\text { N/A } \\
0 \\
65 \\
0 \\
0 \\
56 \\
20 \\
\text { N/A } \\
\text { N/A }\end{array}$ & $\begin{array}{r}74 \\
35 \\
38 \\
118 \\
0 \\
75 \\
80 \\
30 \\
46 \\
5\end{array}$ \\
\hline $\begin{array}{l}\text { Mean } \\
(\text { SD) }\end{array}$ & $121(25)$ & $153(29)$ & $95(10$ & $103(22)$ & $25(25)$ & $50(35)$ \\
\hline
\end{tabular}

N/A, not available.

Cardiac catheterisation and angiography were performed after sedation and local anaesthesia. Left ventricular peak systolic pressure was measured during both catheterisations in all 10 patients, and pressure drops in peak systolic pressures between the left ventricle and aorta were measured in both catheterisations in seven (table 2). Right ventricular peak systolic pressure was measured during both catheterisations in eight patients, and the pressure drops in peak systolic pressure between the right ventricle and the peripheral pulmonary artery were measured in five (table 3 ). The mean ages at first and second catheterisations were 2 years 5 months and 9 years 1 month, respectively (table 1 ). Median ages were one and nine years.

For statistical analysis we used a paired $t$ test.

\section{Results}

Left ventricular peak systolic pressure increased significantly with time, from a mean of $121 \mathrm{~mm} \mathrm{Hg}$ (range $83-170 \mathrm{~mm} \mathrm{Hg}$ ) to a mean of $153 \mathrm{~mm} \mathrm{Hg}$ (range $87-200 \mathrm{~mm} \mathrm{Hg})(p<0.01)$. In only one

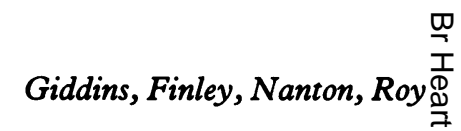

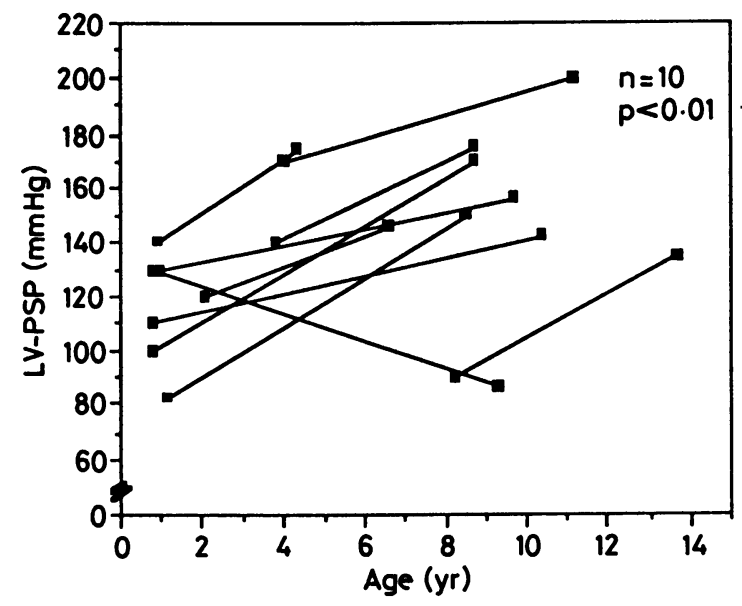

Fig 1 Left ventricular peak systolic pressure ( $L V-P S P)$ in ten patients according to age at catheterisation. Each line represents the change in an individual patient.

patient (case 10) did the pressure decrease (fig 1). $\vec{\oplus}$ Aortic pressures were not measured during three 6 initial catheterisations in infants, so serial data on the peak systolic pressure gradient between the left ventricle and aorta were available for only seven $\bar{\partial}$ patients. There was a significant increase with time, $\stackrel{0}{\circ}$ from a mean value of $25 \mathrm{~mm} \mathrm{Hg}$ (range $0-65 \mathrm{~mm} \mathrm{Hg}$ ) $\stackrel{\perp}{\perp}$ to a mean of $50 \mathrm{~mm} \mathrm{Hg}$ (range $0-118 \mathrm{~mm} \mathrm{Hg}$ ) $\overrightarrow{\vec{F}}$ $(p=0.01)$. In no case did the gradient decrease, although in one patient no gradient was apparent at $כ$ either study (fig 2). Left ventricular angiography showed a significant degree of supravalvar aortic deformity in all patients, whether or not there was a pressure gradient (fig 5).

There was a significant decrease in right ventricular peak systolic pressure with time, from a mean of $52 \mathrm{~mm} \mathrm{Hg}$ (range $16-96 \mathrm{~mm} \mathrm{Hg}$ ) to 28 $\mathrm{mm} \mathrm{Hg}$ (range $20-38 \mathrm{~mm} \mathrm{Hg}$ ) $(\mathrm{p}<0.05)$. In one case only was there an increase of pressure with time

Table 3 Right heart haemodynamic function

\begin{tabular}{|c|c|c|c|c|c|c|c|c|}
\hline \multirow[b]{2}{*}{ Patient } & \multicolumn{2}{|c|}{$\begin{array}{l}\text { Right ventricular (RV) peak } \\
\text { systolic pressure (PSP) } \\
(\mathrm{mm} H g)\end{array}$} & \multicolumn{2}{|c|}{$\begin{array}{l}\text { Main pulmonary artery } \\
P S P(\mathrm{~mm} H g)\end{array}$} & \multicolumn{2}{|c|}{$\begin{array}{l}\text { Peripheral pulmonary artery } \\
(P P A) P S P(\mathrm{~mm} H g)\end{array}$} & \multicolumn{2}{|c|}{$\begin{array}{l}R V-P P A P S P \\
\text { gradient }(\mathrm{mm} \mathrm{Hg})\end{array}$} \\
\hline & Cath I & Cath 2 & Cath 1 & Cath 2 & Cath 1 & Cath 2 & Cath 1 & Cath 2 \\
\hline $\begin{array}{l}1 \\
3 \\
5 \\
6 \\
7 \\
8 \\
9 \\
10 \\
\text { Mean (SD) }\end{array}$ & $\begin{array}{l}65 \\
96 \\
30 \\
16 \\
50 \\
42 \\
32 \\
84 \\
52(26)\end{array}$ & $\begin{array}{l}20 \\
34 \\
38 \\
24 \\
26 \\
34 \\
22 \\
31 \\
28(6)\end{array}$ & $\begin{array}{l}54 \\
N / A \\
30 \\
12 \\
43 \\
42 \\
32 \\
N / A \\
36(13)\end{array}$ & $\begin{array}{l}18 \\
34 \\
29 \\
22 \\
18 \\
34 \\
19 \\
33 \\
26(7)\end{array}$ & $\begin{array}{l}\text { N/A } \\
15(R, L) \\
15(R) \\
10(L) \\
25(R) \\
N / A \\
32(L) \\
N / A \\
19(8)\end{array}$ & $\begin{array}{l}\text { N/A } \\
16(L) \\
21(L) \\
22(L) \\
14(R) \\
\text { N/A } \\
18(L) \\
34(L) \\
21(6)\end{array}$ & $\begin{array}{l}\text { N/A } \\
81 \\
15 \\
6 \\
25 \\
N / A \\
0 \\
N / A \\
25(29)\end{array}$ & $\begin{array}{l}\text { N/A } \\
18 \\
17 \\
2 \\
12 \\
\text { N/A } \\
4 \\
0 \\
9(7)\end{array}$ \\
\hline
\end{tabular}

$R$, right; $L$, left; N/A, not available. 
Williams's syndrome: natu'al course

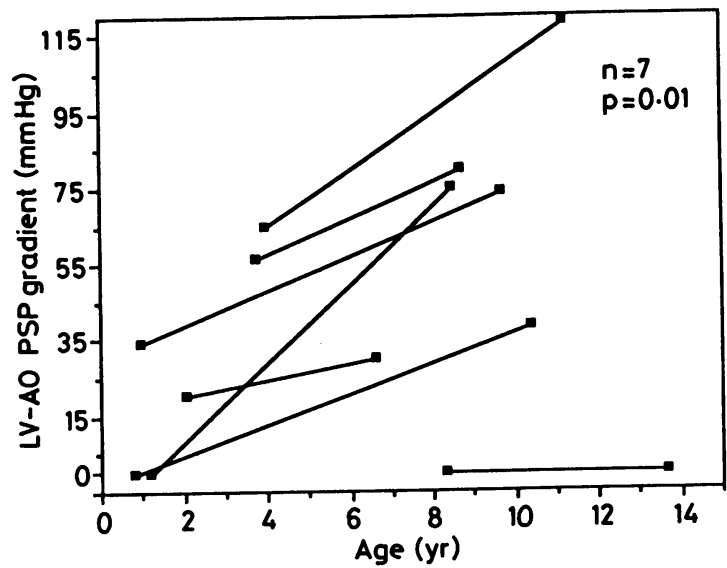

Fig 2 Peak systolic pressure drop between the left ventricle and aorta ( $L V$-Ao PSP) in seven patients according to age at catheterisation.

to a value greater than $30 \mathrm{~mm} \mathrm{Hg}$. The most impressive decreases were in those patients with the highest initial pressures (fig 3). Because the peripheral pulmonary arteries were not entered in three patients, serial data on peak systolic pressure gradients between the right ventricle and peripheral pulmonary artery were available only for five patients and changes were not statistically significant (fig 4).

Supravalvar aortic stenosis and peripheral pulmonary artery stenosis were the only lesions identified at catheterisation.

Decreased right ventricular pressures were associated with striking changes in the angiographic appearance of the pulmonary arteries (fig 6). At the first catheterisation of patient number 10 at nine months of age, right ventricular peak systolic pres-

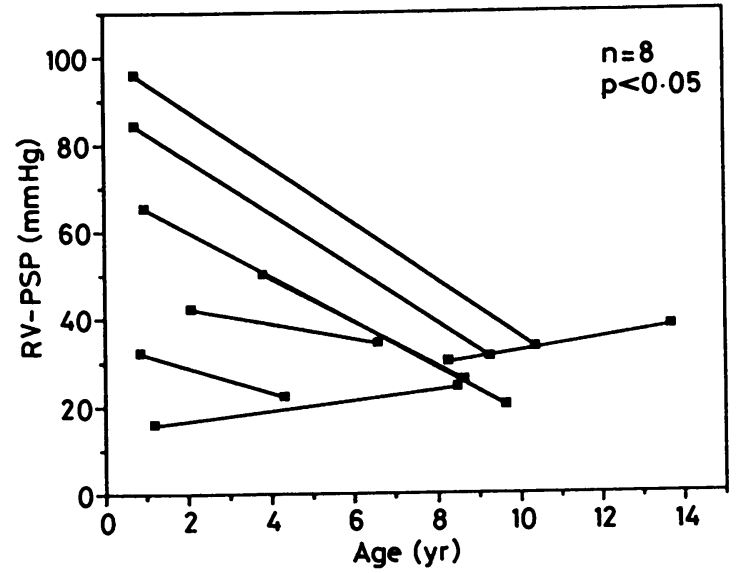

Fig 3 Right ventricular peak systolic pressure ( $R V-P S P$ ) in eight patients according to age at catheterisation.

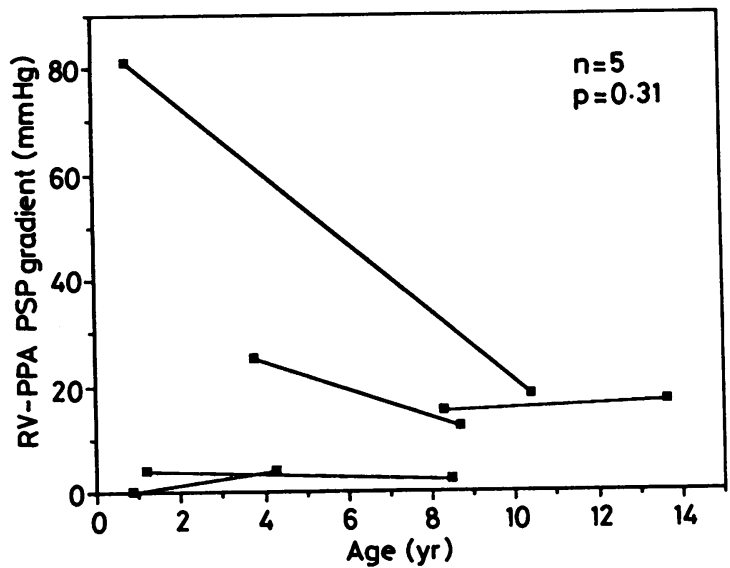

Fig 4 Peak systolic pressure drop between the right ventricle and peripheral pulmonary artery (RV-PPA PSP) in five patients according to age at catheterisation.

sure was $84 \mathrm{~mm} \mathrm{Hg}$ and the pulmonary arteries were diffusely narrow. At the second catheterisation when the patient was nine the right ventricular peak systolic pressure had dropped to $31 \mathrm{~mm} \mathrm{Hg}$ and the pulmonary arteries appeared normal.

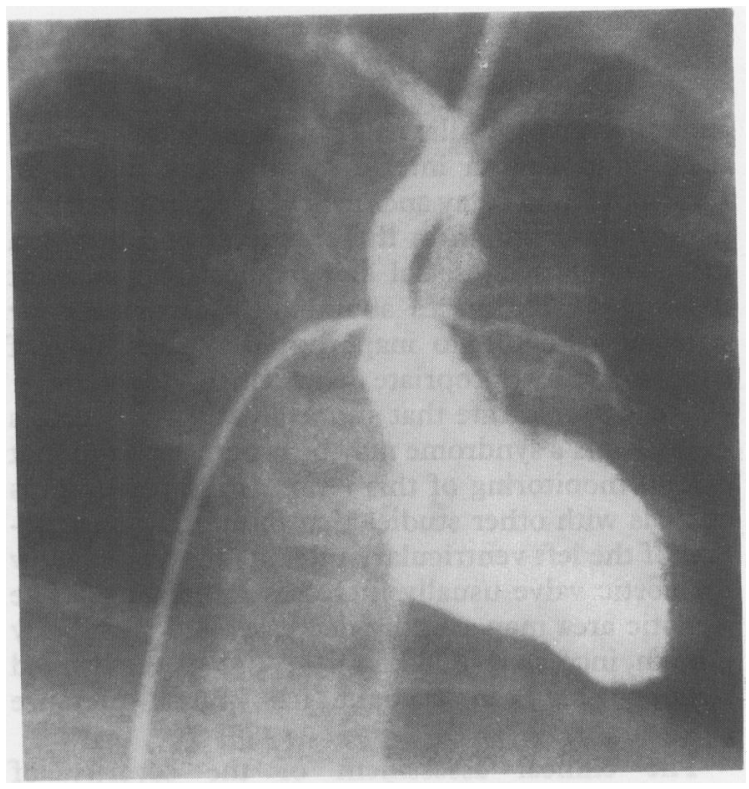

Fig 5 Posteroanterior view of a left ventricular angiogram with the catheter through a patent foramen ovale and mitral valve. This shows distinctive supravalvar aortic narrowing with absence of post-stenotic dilatation of the ascending aorta. Considerable ventricular hypertrophy is suggested by the position of the epicardial coronary vessels. A ductus diverticulum is seen at the distal aortic arch. 

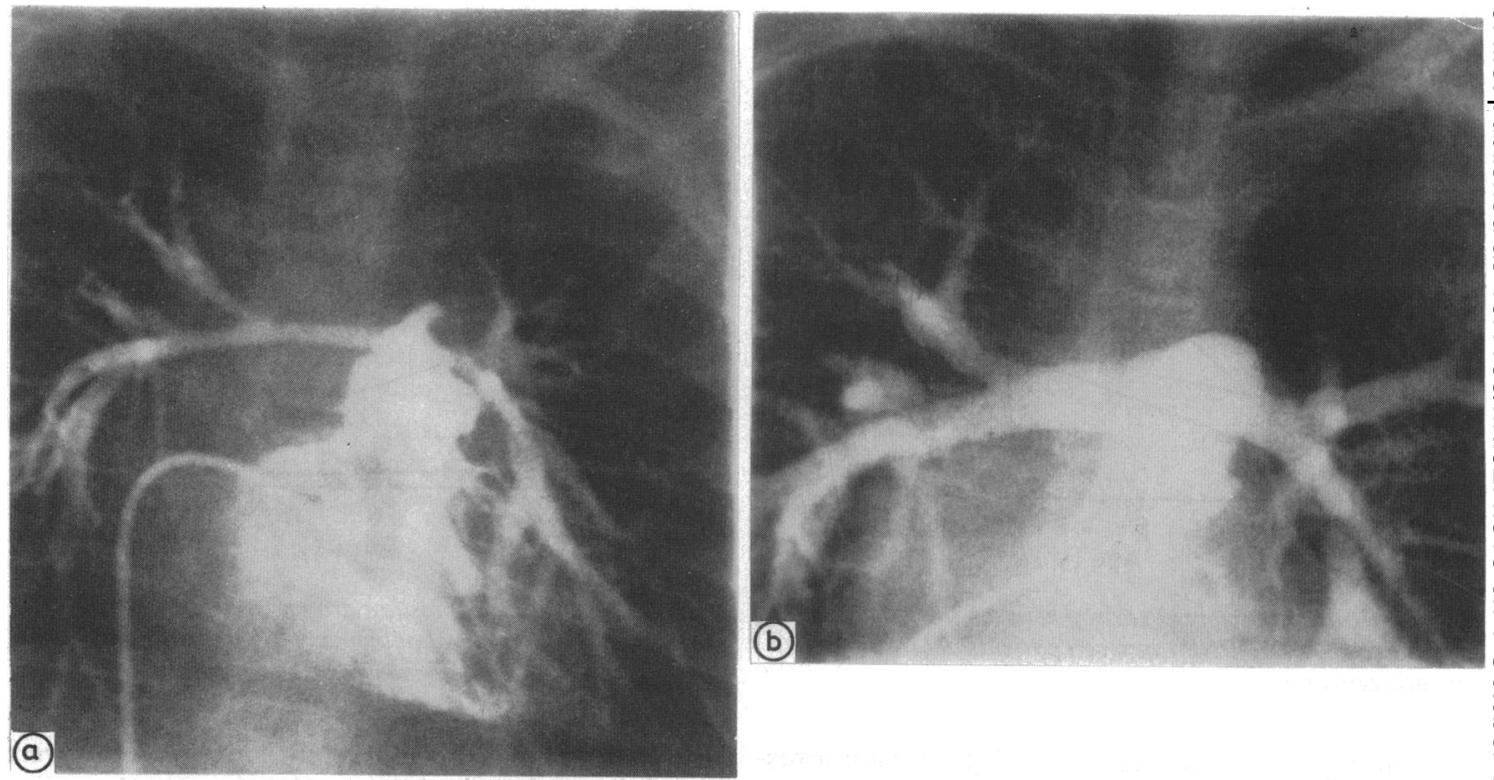

Fig 6 (a) Posteroanterior view of a right ventricular angiogram with the catheter across the tricuspid valve. The patient (case 10) was nine months old and the right ventricular peak systolic pressure (RV-PSP) was $80 \mathrm{~mm} \mathrm{Hg}$. There is diffuse peripheral pulmonary artery narrowing. (b) Right ventricular angiogram of the same patient at nine years of age. $R V$-PSP was $31 \mathrm{~mm} \mathrm{Hg}$, and the pulmonary arteries appear normal.

\section{Discussion}

In patients with Williams's syndrome subtle clinical manifestations can interfere with early diagnosis. Developmental delay and obstructive cardiovascular lesions are common in these patients and they can make both psychosocial and medical management difficult. Uncertainties about likely cardiovascular outcome can lead to inappropriate counselling of parents and inappropriate management decisions.

Our data indicate that supravalvar aortic stenosis in Williams's syndrome may be progressive and that careful monitoring of this lesion is indicated. This accords with other studies that found that obstruction of the left ventricular outlet at, above, or below the aortic valve usually increases in severity. ${ }^{4}$ The stenotic area may actually decrease; and with body growth, increased blood flow through an unchanged stenotic area can account for higher pressure gradients.

The clinical assessment of the severity of supravalvar aortic stenosis can be difficult. In contrast with valvar lesions, there is rarely an ejection click and often murmur transmission is more prominent to the cercival area. ${ }^{5}$ The electrocardiographic changes of left ventricular hypertrophy are present only with severe obstruction.5 Doppler assessment of supravalvar aortic stenosis is probably reliable, but has not been studied extensively in patients with Williams's syndrome. Cardiac catheterisation remains the most valuable diagnostic technique for assessment of this lesion. This must be done with care, however, as patients with Williams's syndrome and widespread vascular or coronary $\vec{\phi}$ involvement can be at increased risk of unexpected death at catheterisation. ${ }^{6}$

Our data also indicate a strong probability that peripheral pulmonary stenosis in Williams's syn- of drome will improve spontaneously. Decreasing right ventricular pressures with age have been reported before, and these were thought to be caused by transient obstruction of the right ventricular outflow tract. $^{2}$ We found that pressure in the main pulmonary artery was high on initial catheterisation, and this suggests more distal obstruction.

In two of the three patients with the most impressive decreases in right ventricular pressure the $\sigma$ gradient from the left ventricle to the aorta increased 0 over the same period. This "self-correcting" pulmonary arterial behaviour contrasts with the $\stackrel{\mathcal{P}}{+}$ "progressive" aortic behaviour. Further investiga- $\frac{T}{\circ}$ tion of possible mechanisms may assist efforts to treat other forms of pulmonary hypoplasia. Certainly, $\stackrel{\square}{\square}$ with the availability of dilatation procedures ${ }^{7}$ and $\stackrel{\mathbb{Q}}{\varrho}$ vascular stents ${ }^{8}$ for treatment of arterial obstructions, $\bar{\sigma}$ knowledge of lesions that may improve spon- 
Williams's syndrome: natural course taneously is most important.

We thank Mrs Sherrin Markiewich, Dr G W Vick III, and Dr A N Pelech for their assistance in preparing this paper.

\section{References}

1 Jones KL. Smith's recognizable patterns of human malformation. Philadelphia: WB Saunders, 1988:106.

2 Folger GM Jr. Further observations on the syndrome of idiopathic infantile hypercalcemia associated with supravalvular stenosis. Am Heart J 1977;93:455-62.

3 Ino $T$, Nishimoto $\mathrm{K}$, Iwahara $\mathrm{M}$, et al. Progressive vascular lesions in Williams-Beuren syndrome. Pediatr Cardiol 1988;9:55-8. 